\title{
INTERVENTION POLICY OF THE BOJ: A UNIFIED APPROACH
}

\author{
MiCHEL BEINE \\ OSCAR BERNAL \\ JEAN-YVES GNABO \\ CHRISTELLE LECOURT
}

\author{
CESIFO WORKING PAPER No. 1894 \\ CATEgory 6: Monetary Policy And InTERnAtional FinANCE \\ JANUARY 2007
}

An electronic version of the paper may be downloaded

- from the SSRN website:

- from the RePEc website:

www.SSRN.com

- from the CESifo website:

www.RePEc.org

www.CESifo-group.de 


\title{
INTERVENTION POLICY OF THE BOJ: A UNIFIED APPROACH
}

\begin{abstract}
Intervening in the FX market implies a complex decision process for central banks. Monetary authorities have to decide whether to intervene or not, and if so, when and how. Since the successive steps of this procedure are likely to be highly interdependent, we adopt a nested logit approach to capture their relationships and to characterize the prominent features of the various steps of the intervention decision. Our findings shed some light on the determinants of central bank interventions, on the so-called secrecy puzzle and on the identification of the variables influencing the detection of foreign exchange transactions by market traders.
\end{abstract}

JEL Code: E58, F31, G15.

Keywords: FX intervention, secrecy puzzle, market detection, nested logit.

Michel Beine

University of Luxembourg

162a av. de la Faiencerie

1511 Luxembourg

Luxembourg

michel.beine@uni.lu

Jean-Yves Gnabo

University of Namur

rue de Bruxelles 61

5000 Namur

Belgium

jean-yves.gnabo@fundp.ac.be
Oscar Bernal

Free University of Brussels

Ave. Franklin D Roosevelt, 50, PC 140

1050 Brussels

Belgium

obernal@ulb.ac.be

Christelle Lecourt

University of Namur

rue de Bruxelles 61

5000 Namur

Belgium

christelle.lecourt@fundp.ac.be

December 22, 2006.

Financial support from the Belgian National Fund for Scientific Research (FRFC Program) is gratefully acknowledged. We would like to thank Cinzia Cirillo for computational assistance as well as Agnès Bénassy-Quéré for providing us with estimates of the fundamental exchange rate value. We are also grateful to Gabriele Galati for sharing his dataset that allows to make some cross-checks with our findings. We thank participants of seminars and conference held in Luxembourg, Paris Nanterres and at the Bank of Canada for comments and suggestions, and in particular G. Galati, C. De Souza and R. Miller. The usual disclaimer applies. 


\section{Introduction}

Direct central bank interventions remain an important policy instrument used by major central banks to influence the dynamic of the foreign exchange (FX) market. In the 1980s and the 1990s, the US Federal Reserve (Fed) and the Bundesbank relied extensively on unilateral and concerted operations to counteract what they considered to be undesirable developments in major exchange rates. While the US and European monetary authorities have become more reluctant to intervene over time, the Bank of Japan (BoJ) has remained very active. Since the beginning of the 1990s, the BoJ has been present in the foreign exchange market more than 300 times and has played a major role by conducting very large-scaled operations (such as those undertaken in June 1998 when the Bank of Japan purchased more than 20 billion USD on a single day).

Intervening in the FX market is a complex process that displays several dimensions which are not always easy for researchers to understand. A first important dimension concerns the determinants of interventions. This has been extensively explored in the empirical literature (Almekinders, 1995; Baillie and Osterberg, 1997; Ito, 2003; Ito and Yabu, 2004; Kearns and Rigobon, 2005; Bernal, 2006 and Bernal and Gnabo, 2006). The main results suggest that interventions tend to be conducted to counteract large deviations of the exchange rate from past levels. These studies have also highlighted the existence of non-intervention bands, suggesting that monetary authorities incur significant costs when intervening on the foreign exchange markets.

Another, less-studied, dimension involves the type of intervention conducted. Basically, when intervening, monetary authorities might or might not wish to conceal their operations. As emphasized by Sarno and Taylor (2001) and Vitale (2006), central banks' interventions usually aim to provide market participants with some private information, and so, according to the signalling theory, the use of secret operations is puzzling. The BoJ has used secret interventions intensively in recent years, which suggests that this issue is of much more than purely academic interest. While a couple of theoretical rationales have been provided to the use of secret interventions (Bhattacharya and Weller, 1997; Vitale, 1999 and Chiu, 2003), only a few empirical studies have attempted to identify the determinants of this choice. In particular, Beine and Bernal (2006) have explored this topic by studying the share of interventions by the BoJ which were hidden from the market in recent years.

A final dimension is the detection of foreign exchange operations by market participants. While the central banks can ensure that the market detects their interventions by confirming their operations, when it opts for secrecy it cannot be certain that its actions will remain undetected. Beine and Bernal (2006) have investigated the circumstances in which the market remains unaware of interventions. They suggest that FX market traders can detect the presence of the central bank more or less easily depending on the features of the operation (such as the size or the timing). A failure in the strategy of maintaining secrecy about an intervention the central bank wanted to hide would obviously erode its credibility and 
reputation. Therefore, a good understanding of the features involved in the process of detecting those operations might be important for central banks' policy purposes.

Most studies have dealt with these three dimensions separately. One of the primary aims of the present paper is to consider them as interdependent processes, and to identify the main determinants of the various outcomes peculiar to the intervention process. Using data on the intervention policy of the BoJ over the period 1991-2004, we estimate a discrete choice model describing each of the above dimensions. More precisely, we use a nested logit model that allows to simultaneously identify the determinants of the intervention activity, the incentives for the central bank to opt for secrecy, and the variables at stake in the detection of $\mathrm{FX}$ operations by market participants.

This approach offers two main advantages that allow some new light to be shed on key elements of the intervention policy. First, the various dimensions related to the intervention activity are likely to be highly interdependent. That is, an element related to one dimension of the intervention process might well influence the outcome of another dimension. For instance, the fact that the central bank can intervene with a fairly good probability of not being detected by the market may increase the scope for intervention. Another implication of the interdependence of these dimensions is that they might be influenced by the same set of determinants. An example of this is provided by communication policy. Official statements about the exchange rate policy or the general stance of the FX market can increase or decrease the use of interventions (depending on whether statements are considered as substitutes for or complements to actual FX operations). Furthermore, since authorities' communication strategies generally aim to increase the transparency of their policy, official statements might be expected to lower the propensity to use secret interventions. The estimation of a nested logit describing the various steps of the intervention process then allows their interdependence to be taken into account, and leads to a better understanding of the exchange rate policy.

A second advantage concerns the way we specifically address the secret intervention puzzle. Two conditions must be fulfilled for an intervention to remain effectively secret: (i) the central bank must decide to conceal the operation; and (ii) market participants must not detect it. In order to assess the statistical significance of the determinants influencing the choice of secrecy by the central bank and the detection process by market participants, it is necessary to make a clear distinction between interventions the BoJ wanted to make public and those it wanted to keep secret. This is achieved by using auxiliary information about rumors, as in Gnabo and Lecourt (2005)'s recent work. This procedure overcomes one limitation of Beine and Bernal (2006)'s work, which was unable to distinguish public interventions from those which the authorities had failed to keep secret, and had to make an ex ante distinction between the two sets of explanatory variables. Our approach allows to consider the choice of secrecy made by central banks and the detection of official trades by market participants as different steps in the intervention process. Furthermore, it allows the secrecy puzzle to be considered within the whole set of decisions 
made by central banks when intervening on the FX market.

The paper is organized as follows. Section 2 clarifies a set of useful concepts, while Section 3 reviews the existing literature. Section 4 presents the nested logit model which allows the intervention policy to be analyzed as a sequential process. It also discusses specification issues. Section 5 gives details of the data used in the econometric analysis, while Section 6 reports and discusses the econometric results, and Section 7 presents our conclusions.

\section{Some useful definitions}

Before discussing the empirical literature and describing our analysis, it might be useful to clarify the concepts surrounding interventions on the FX markets. To this end, we present below several useful definitions that should help the reader to have a clear overview of the concepts used in this paper.

- An FX intervention carried out by a central bank is a direct sale or purchase of foreign currency on the spot market that is intended to influence the value of the exchange rate. This intervention is unilateral if there is a single central bank present in the market. If two or more central banks undertake the same intervention (same market, same direction and on the same day) with their own funds, the intervention is considered coordinated. ${ }^{1}$

- An official intervention is an intervention which is confirmed by official data released after some time lag (usually three to six months) by the central banks themselves. The data allows interventions that have actually taken place to be identified.

- A secret intervention is an intervention that the central bank wants to carry out in a discreet way. By contrast, a public intervention is an operation that the central bank wants to disclose to market participants, either through the way the orders are given to FX traders or through official statements aimed at drawing the attention of market participants.

- A detected intervention is a central bank intervention (secret or public) which is detected by market participants (usually FX dealers) the day it is carried out. ${ }^{2}$ On the other hand, an undetected intervention is an operation that market agents are unaware of on the day it is conducted.

Importantly, the distinction between "public" and "secret" interventions relies on the willingness of the central bank to make the operation known to market participants. This contrasts with the notion of "detected" or "undetected" interventions which relies on an ex post assessment of the perception of

\footnotetext{
${ }^{1}$ Interventions conducted on behalf of other central banks are not considered coordinated. Coordination requires each central bank to intervene with its own funds.

${ }^{2}$ Another definition of a detected intervention is that it is an intervention which is confirmed by official data. Our definition refers to a short-run notion of detection and secrecy, and is consistent with most studies of secret operations (see, for instance, Dominguez, 1998).
} 
these operations by market participants (for instance by newswire reports). This means that a secret intervention can be detected, despite the efforts of the central bank to conceal it, if FX dealers have an efficient detection system in place. In other words, the fact that the central bank tries to keep an intervention secret is not sufficient to ensure that it remains undetected. The combination of the secret/public distinction and the detection process leads to a further distinction: detected secret interventions and undetected secret interventions (also called pure secret interventions). By definition, public interventions are always detected.

\section{The previous literature}

The empirical literature devoted to decisions on interventions can be divided into (i) studies focusing on the intervention decision itself; (ii) studies rationalizing the use of secret interventions; and (iii) analyses of the processes by which market traders detect central bank operations. Most of these studies have dealt with these issues separately, without taking into account their interdependence. One of the primary aims of this paper is to fill this gap and to identify the main determinants of the various outcomes of the intervention process. To highlight the contribution of this paper, we first briefly review the existing literature.

\subsection{Intervention decisions}

Most papers dealing with central banks reaction function (Almekinders, 1995; Ito, 2003; Ito and Yabu, 2004; Kearns and Rigobon, 2005 and Bernal, 2006) derive it from a loss-function minimization program by assuming specific processes for the exchange rate dynamic (e.g. random walk or auto-regressive processes). Losses increase with deviations of the exchange rate from the central bank's target (several definitions have been used, such as the fundamental equilibrium rate or a weighted target derived from past exchange rate levels). The central bank is also assumed to incur a loss if it faces excessive exchange rate volatility. The results of these studies indicate quite robustly that intervention policies are designed to counter large deviations of the exchange rate from the central bank's target. More generally, there is considerable consensus that central banks tend to adopt a leaning-against-the-wind strategy to counter inappropriate exchange rate dynamics. Research on the volatility issue provides less robust results. It indicates, however, that central banks tend sometime to intervene to calm disorderly markets (Baillie and Osterberg, 1997). In particular, Bernal and Gnabo (2006) find that central banks seem to be more concerned by increases in the daily volatility rather than by overall volatility levels or regimes. The weaker evidence on volatility may come from the fact that interventions themselves can stimulate volatility. Another explanation may be that the volatility measures generally used in empirical studies are generated regressors (Pagan, 1984). 
Empirical results also indicate that current interventions depend strongly on past intervention activity. This reflects the clustering pattern of foreign exchange operations that can be explained by their related cost (which is reduced if interventions are conducted several days in a row according to Ito and Yabu, 2004). There is also considerable debate about whether actual and oral interventions are substitutes or complements. Fratzscher (2004) has shown that oral interventions can be a good alternative to actual FX purchases and sales, suggesting that these instruments are substitutes. However, Beine et al. (2004) have shown that some of these statements can be used as efficient complementary tools. More generally, Bernal and Gnabo (2006) argue that the substitute/complement role of oral and actual interventions depends on the overall market conditions.

\subsection{Secret intervention strategy}

Central banks can adopt different intervention strategies. In particular, they have to decide whether to intervene secretly or publicly. ${ }^{3}$ However the use of secret interventions remains a puzzle, given that the main theory used to explain how interventions work (the signaling channel framework) fails to explain their use (Sarno and Taylor, 2001 and Vitale, 2006). Indeed, this theory suggests that an intervention has to be detected by market participants in order to be effective, as it works by influencing their expectations concerning the future value of exchange rates. Nevertheless, theoretical arguments have been developed to rationalize the use of secret interventions (see, inter alia Vitale, 1999 and Chiu, 2003). The main reasons suggested involve the inconsistency of an intervention with the objective of reducing the misalignment, the bad past performance of the intervention activity, and, generally, the low likelihood of conducting a successful intervention.

A first step in testing the relevance of these variables was provided by Beine and Bernal (2006) who use a single logit approach. ${ }^{4}$ They analyzed the probability of an intervention being conducted secretly by assuming they were able to disentangle the determinants of the detection process from the determinants of the decision to use secret operations. In contrast with Chiu (2003)'s conjecture, their results indicate that authorities tend to avoid the use of secret interventions when their past interventions have failed to deliver the intended outcome. On the other hand, the results support the Vitale (1999)'s view, in that secret interventions tend to be used when the operation runs counter to that which would be needed to reduce the misalignment.

\footnotetext{
${ }^{3}$ Using evidence from recent BoJ practices, Beine and Lecourt (2004) conclude that secret interventions constitute an important stabilization tool.

${ }^{4}$ Another interesting approach is provided by Neely (2006)'s updated survey of authorities' beliefs about interventions. He asked 27 central banks why they opted for secrecy. Most of the responses appear to be consistent with the variables tested by Beine and Bernal (2006) and in this paper.
} 


\subsection{Detected and undetected secret interventions}

A central bank's adoption of a covert or public intervention strategy has an impact on other characteristics of its interventions, such as their size, frequency, and the degree of international coordination. In turn, these elements define the exact nature of the interventions and determine whether or not the market can easily detect the central bank's operations. This arises directly from the fact that by choosing a specific disclosure strategy, the central bank explicitly chooses to maximize or minimize the signal sent to the market. ${ }^{5}$ This has been discussed by Beine and Lecourt (2004) and Beine and Bernal (2006) who show that large, frequent, and internationally coordinated interventions have a higher probability of being detected by the market than small, sporadic and unilateral interventions. According to Neely (2006), these findings are strikingly in accord with central bankers' opinions about the key variables influencing the detection process. These findings thus provide evidence about how central banks should intervene if they want the signal sent to the market to be clear, strong and efficient with respect to their general policy. These results also emphasize the existence of conflicting interests when FX authorities decide to conceal their operations. In this case most of the effect occurs through the portfolio and microstructure channels, so that there is a trade-off between the authorities' desire to increase the portfolio effects and their wish to keep their intervention secret.

\section{Econometric approach}

\subsection{A nested logit model}

As discussed in the previous section, the intervention process involves several distinct steps (the intervention decision, the choice of intervention strategy, and the market's perception) that should all be incorporated into a single model. Nested logit specifications (Ben-Akiva, 1973) extend the well-known multinomial logit model by relaxing the independence of irrelevant alternatives (IIA) hypothesis. The IIA hypothesis is a central assumption of multinomial logit models which holds that the ratio of the probabilities of choosing any two alternatives should be independent of the choice set. That is, any change in an attribute of one alternative must have the same impact on the probability of choosing the other alternative. This assumption may be restrictive, especially if the decision-taking agent considers some of the alternatives to be similar. Nested logit models relax this hypothesis by allowing the different alternatives to be organized in groups according to their similarity and by letting within-group cross-elasticities be larger than those between groups (for a comprehensive discussion, see McFadden, 1984). ${ }^{6}$

\footnotetext{
${ }^{5}$ According to the microstructure approach to FX interventions (see Lyons, 2001 and Evans and Lyons, 2001), the secrecy of orders flows allows an intervention to be indistinguishable from private trades.

${ }^{6}$ Hausman and McFadden (1984) propose a test of the validity of the IIA hypothesis. However this test suffers from several drawbacks, and so, we used the Small-Hsiao test instead (Small and Hsiao, 1985).
} 
Our analysis consists of estimating a three-levels nested logit, in line with the discussion of the intervention process in the previous section. In such a model, the set of choices faced by an individual (here the central bank) is partitioned in nests $(i=1, \ldots, N)$ and sub-nests $\left(j=1, \ldots, N_{i}\right)$ of alternatives $\left(k=1, \ldots, N_{i j}\right)$ according to their similarity. Importantly, the utility associated with alternative $k$ in sub-nest $j$ of nest $i$ not only depends on its specific attributes, but also on the attributes of the nest and sub-nest in which it is located. This is illustrated by the random utility function in equation (1) where $\tilde{V}_{i j k}, \tilde{V}_{i j}$ and $\tilde{V}_{i}$ are the systematic part of the utility respectively associated with alternative $k$, sub-nest $j$ and nest $i$ respectively. $\epsilon_{i j k}, \epsilon_{i j}$ and $\epsilon_{i}$ are independent extreme value distributed error terms with $\sigma_{i j}$, $\sigma_{i}$ and $\sigma$ as their respective scale parameters.

$$
U_{i j k}=\tilde{V}_{i j k}+\epsilon_{i j k}+\tilde{V}_{i j}+\epsilon_{i j}+\tilde{V}_{i}+\epsilon_{i}
$$

The probability model for this problem is then given by equation (2) where $P_{i j k}, P_{k \mid i, j}, P_{j \mid i}$ and $P_{i}$ denote the probability of choosing alternative $k$, sub-nest $j$ and nest $i$ respectively.

$$
P_{i j k}=P_{k \mid i, j} \times P_{j \mid i} \times P_{i}
$$

Given the assumed distributions of $\epsilon_{i j k}$ and considering $\tilde{V}_{i j k}=\alpha X_{i j k}$ where $X_{i j k}$ is the vector of specific attributes of alternative $k$ and $\alpha$ is a parameter to be estimated, equation (3) is the analytical form of $P_{k \mid i, j}$ (for details, see Maddala, 1983). It indicates that the probability of choosing alternative $k$ is the ratio of its associated exponentiated utility and the total exponentiated utility of all the other alternatives within sub-nest $j$ of nest $i . \sigma_{i j}$ is a measure of the similarity or independence of alternatives within sub-nest $j$ (i.e. for a given sub-nest, the contribution of an alternative to the total exponentiated utility increases with its degree of independence from the other alternatives of the same sub-nest).

$$
P_{k \mid i, j}=\frac{e^{\sigma_{i j} \tilde{V}_{i j k}}}{\sum_{n} e^{\sigma_{i j} \tilde{V}_{i j n}}}=\frac{e^{\sigma_{i j}\left(\alpha X_{i j k}\right)}}{\sum_{n} e^{\sigma_{i j}\left(\alpha X_{i j n}\right)}}
$$

By defining a pseudo-utility or composite utility function for each sub-nest and nest, it is possible to derive the analytical forms of $P_{j \mid i}$ and $P_{i}$. These pseudo-utilities should depend not only on the specific attributes of the sub-nest or nest but also on the utility associated with each alternative that they contain. Generally speaking, the utility of upper levels of the model should encompass the utility of lower levels. Equations (4) and (5) correspond to these pseudo-utility functions. $I_{i j}$ and $I_{i}$ are inclusive values or log-sums that permit the lower level utility to be incorporated into the upper level. ${ }^{7}$

\footnotetext{
${ }^{7}$ The software used to estimate our model (Alogit) uses a different definition of the pseudo-utility functions. It considers $V_{i j}^{\prime}=\tilde{V}_{i j}+\frac{1}{\sigma_{i j}} \log \left(\sum_{n} e^{\tilde{V}_{i j n}}\right)$ and $V_{i}^{\prime}=\tilde{V}_{i}+\frac{1}{\sigma_{i}} \log \left(\sum_{m} e^{V_{i m}^{\prime}}\right)$. Basically, the difference lies in the fact that Alogit does not measure the utilities of upper levels in the same units as those of lower levels, principally for programming simplicity. However, if needed, consistency of the units can be achieved by modifying the model slightly. This is what we did when considering the isolated alternatives "No Intervention" and "Public" to be contained in a specific sub-nest and nest (see
} 


$$
\begin{gathered}
V_{i j}^{\prime}=\tilde{V}_{i j}+\frac{1}{\sigma_{i j}} \log \left(\sum_{n} e^{\sigma_{i j} \tilde{V}_{i j n}}\right)=\tilde{V}_{i j}+\frac{1}{\sigma_{i j}} I_{i j} \\
V_{i}^{\prime}=\tilde{V}_{i}+\frac{1}{\sigma_{i}} \log \left(\sum_{m} e^{\sigma_{i} V_{i m}^{\prime}}\right)=\tilde{V}_{i}+\frac{1}{\sigma_{i}} I_{i}
\end{gathered}
$$

Hence, setting $\tilde{V}_{i j}=\beta Z_{i j}$ and $\tilde{V}_{i}=\gamma W_{i}$ where $Z_{i j}$ and $W_{i}$ are the specific attributes of sub-nest $j$ and nest $i$ respectively, and $\beta$ and $\gamma$ are the parameters to be estimated, $P_{j \mid i}$ and $P_{i}$ are given by equations (6) and (7). Again, $\sigma_{i}$ and $\sigma$ measure the level of independence of the elements of sub-nest $j$ and nest $i$ respectively.

$$
\begin{gathered}
P_{j \mid i}=\frac{e^{\sigma_{i} V_{i j}^{\prime}}}{\sum_{m} e^{\sigma_{i} V_{i m}^{\prime}}}=\frac{e^{\sigma_{i}\left(\beta Z_{i j}+\frac{1}{\sigma_{i j}} I_{i j}\right)}}{\sum_{m} e^{\sigma_{i}\left(\beta Z_{i m}+\frac{1}{\sigma_{i m}} I_{i m}\right)}} \\
P_{i}=\frac{e^{\sigma V_{i}^{\prime}}}{\sum_{l} e^{\sigma V_{l}^{\prime}}}=\frac{e^{\sigma\left(\gamma W_{i}+\frac{1}{\sigma_{i}} I_{i}\right)}}{\sum_{l} e^{\sigma\left(\gamma W_{l}+\frac{1}{\sigma_{i}} I_{l}\right)}}
\end{gathered}
$$

Equations (3), (6) and (7) determine the three-levels nested logit model estimated in this paper which is designed to analyze the sequential structure of the problem faced by central banks when intervening. This is illustrated in Figure 1 where the top of the diagram (No Intervention v.s. Intervention) describes the intervention decision and basically corresponds to the estimation of the reaction function of the central bank. Therefore, all the variables described by the literature on central bank reaction functions (i.e. the deviation with respect to the central bank's target, the volatility, the recent intervention activity and the communication policy of the central bank), designated by $W$ in equation (7), should be included. Their impact on the intervention decision is measured by the parameter $\gamma$. The mid-level layer (Public v.s. Secret) allows the theoretical arguments for the use of secret interventions to be assessed. The variables included at this level (i.e. inconsistency with respect to the objective of reducing the deviation from the central bank's target, the performance of past interventions, and the likelihood of success) are denoted by $Z$ and their effect on the disclosure strategy of the central bank is captured by $\beta$. Finally, the bottom level corresponds to the detection of the central bank's interventions by market participants. The variables indicated by $X$ (i.e. the size of the intervention, the clustering of interventions, the extent of international coordination, and the success of an intervention) influence the ability of market participants to detect interventions that the central bank wanted to maintain secret. This is measured by parameter $\alpha$ which allows us to explain how interventions should be designed in accord with the disclosure strategy of the central bank.

Estimates of $\alpha, \beta$ and $\gamma$ are obtained by maximum likelihood techniques. ${ }^{8}$ These parameters can only Figure 1).

${ }^{8}$ Note that, for estimation purposes, only $\gamma$ contains a constant. 
Figure 1: Problem faced by the central bank

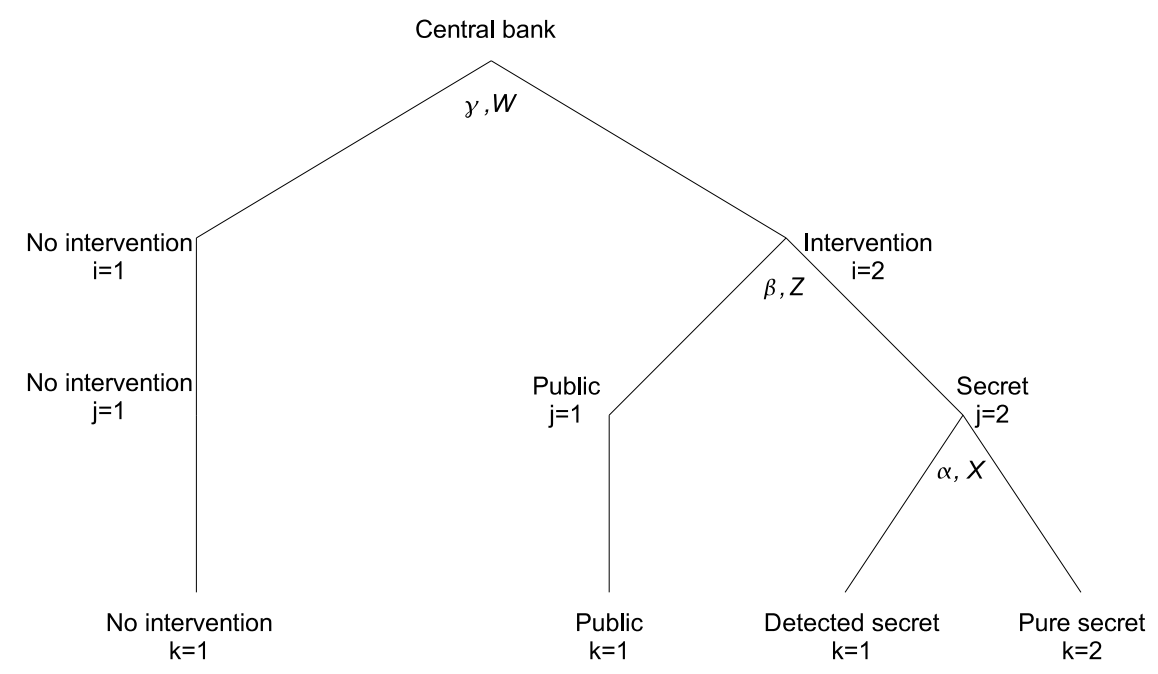

be estimated up to the scale parameters. Since only their ratio is actually meaningful it is then usual to arbitrarily fix (i.e. normalize) the value of the scale parameters. Alogit performs a normalization "from the bottom" (Ben-Akiva, 1973 and Ben-Akiva and Bierlaire, 1999). ${ }^{9}$ That is, it constrains one of the scale parameters at the bottom level of the model. This dramatically simplifies the estimation process (Daly, 1987).

\section{The data}

Data constraints play an important role in assessing the determinants of secret and detected interventions empirically, since this information is not directly observable. In this section, we detail the building of the dataset used to estimate the model made up of equations (3), (6) and (7). We start by focusing on the intervention data, and the way we disentangle first secret and public interventions, and then pure secret and detected secret operations. Then we turn to the description of the data corresponding to variables $X, Z$ and $W$.

\subsection{Dependent variable}

\subsubsection{Official intervention data}

We start with the official data on interventions released by the Japanese authorities. This data is available daily, from 1 April 1991 onwards, on the Japanese Ministry of Finance's website. ${ }^{10}$ For each intervention, the exact date, amount and currencies involved are provided. Our investigation period ends in September

\footnotetext{
${ }^{9}$ We are particularly grateful to Cinzia Cirillo for providing us with Alogit codes and precious advices on the empirical part of the study.

${ }^{10}$ http://www.mof.go.jp/english/e1c021.htm
} 
2004 and encompasses 343 official intervention days. Note that starting with official data (i.e. data on interventions that have actually taken place) allows us to circumvent the issue of spuriously reported interventions (when market participants erroneously believe that an intervention has occurred). This contrasts with studies basing the identification of interventions on unofficial data sources such as news reports (see Dominguez and Frankel, 1993 for a discussion of this practice).

\subsubsection{Using newswire reports to identify public and secret interventions}

The identification of public and secret interventions can be achieved by comparing actual and marketreported interventions (see, inter alia Dominguez, 1998; Beine et al., 2002 and Beine and Lecourt, 2004). While actual interventions can be correctly assessed using official intervention data, different techniques have to be used to determine whether or not market participants were informed that the central bank was in the market. Some previous studies have used reports from financial newspapers (Bonser-Neal and Tanner, 1996 and Dominguez, 1998). This method does not, however, appear to be particularly accurate. Subsequent studies (Galati and Melick, 1999 and Beine and Lecourt, 2004) have shown that news reports from wire sources such as Reuters, Bloomberg and Dow Jones capture many more intervention episodes. This is consistent with Oberlechner and Hocking (2004)'s view that newswire services are the most important sources of information available to traders and often reflect both market participants' perceptions and their interpretations.

In this study, we distinguished between public and secret official interventions by using information provided by newswire reports. To this end we used the online database Factiva (including Dow Jones and Reuters reports) from which news reports can be extracted in real time. ${ }^{11}$ To find reports related to central bank intervention activity, we used the method pioneered by Beine and Lecourt (2004) and Gnabo and Lecourt (2005) that consists of searching for a set of relevant keywords within the main core of the text of the news. Then these reports are classified according to the degree of certainty of the information about the occurrence of the intervention. In turn, this criterion is used first to decompose official interventions into public and secret interventions, and subsequently to decompose the secret interventions into pure secret and detected secret interventions. We discuss this in detail below.

\section{Identifying public interventions}

According to the signaling channel theory, central bank intervention operations convey a signal about the future value of fundamentals. The process of disseminating the signal may be divided into three steps. First, depending on whether the central bank wants its intervention to be perceived or not, some agents detect the presence of the central bank in the market. At this stage, the signal is only seen by a small audience, and may not be considered as publicly known (some privileged agents such as major commercial

\footnotetext{
${ }^{11}$ Factiva offers a wide choice of search tools and features. For details see http://www.factiva.com
} 
banks may be explicitly informed of the intervention by the central bank itself). Afterwards, the news of the intervention is reported by newswire journalists through their personal network of traders, bankers and brokers in the market. Finally, the news is relayed to the whole market through newswires such as "BoJ seen buying dollars at around 104.00 yen in Tokyo - Reuters, August 11, 1993", so definitely making it public. ${ }^{12}$

Public interventions are then identified as those that were firmly or clearly reported in newswires (whether through direct detections by market participants or by official speeches announcing the operation). ${ }^{13}$ Here "clear" means that the report removes any remaining ambiguity concerning the occurrence of the operation and reflects the willingness of the central bank to be seen by the market to be intervening. Examples of this type of news report are given in Table 1.

Table 1: Examples of news reports used to identify public interventions

\begin{tabular}{|c|c|c|}
\hline Date & Sources & Relevant text of the news report \\
\hline September 19, 1994 & Reuters & "BoJ buys dlrs persistently at around 98.60 yen" \\
\hline September 6, 1995 & Dow Jones & "Early Tokyo: dollar surges after BoJ buying" \\
\hline April 10, 1998 & Reuters & "Dollar down sharply vs. yen on BoJ intervention" \\
\hline June 21, 1999 & Reuters & $\begin{array}{l}\text { "Dollar climbs amid BoJ seen continuing to buy dlrs above } \\
\text { Y122- bankers" }\end{array}$ \\
\hline June 21, 1999 & Dow Jones & "N.Y. Early: Dollar up vs. Yen After BoJ intervenes" \\
\hline September 17, 2001 & Dow Jones & "Dollar rises near to Y118 on BoJ FX intervention" \\
\hline October 14, 1999 & Dow Jones & "BoJ conducts Yen-selling intervention" \\
\hline
\end{tabular}

Note: Reports in this table indicate that the market clearly knew that an intervention was taking place in the market.

\section{Identifying secret interventions}

A central bank can also decide to step into the market without drawing traders' attention to its action. Several strategies are available in order to keep an intervention secret (see Beine and Bernal, 2006 for details). For instance, the central bank can intervene in a discreet way by using unilateral operations and low amounts. It can also choose to operate with unusual partners (for example through major foreign banks or brokers). Nevertheless, this can be detected by traders or bankers who suspect that the central bank has placed orders. In turn, these traders might report the news to the market. That is, the central bank's intention to keep its operations secret is not sufficient to ensure that market participants do not detect them. Therefore, secret interventions have to be further split into "pure secret interventions" (i.e. interventions that the central bank managed to keep secret) and "detected secret interventions" (i.e. interventions that were detected by market participants despite the central bank's efforts to conceal them).

Secret interventions are defined as those for which there was either no report at all or a report with

\footnotetext{
${ }^{12}$ Dominguez (2003) suggests that this process may take approximately 15 minutes.

${ }^{13}$ Keywords such as "BoJ", "Bank of Japan" and "interventions" were used to identify clear reports of interventions (i.e. reports with a high degree of certainty).
} 
a high degree of uncertainty. ${ }^{14}$ More precisely, "pure secret interventions" are secret interventions which were not detected by the market, i.e. for which there were no news reports of the intervention at all. Conversely, "detected secret interventions" are secret interventions which were detected by the market: that is for which there was a highly uncertain news report about the intervention. Table 2 provides examples of this type of news report. Given their degree of uncertainty, these news reports can also be called rumors of intervention (Gnabo et al., 2006). ${ }^{15}$ That is, the market suspects that the central bank has intervened, but is not absolutely certain. Importantly, while we do not explicitly analyze the process through which rumors of intervention spread among FX dealers, we use this type of information to make a distinction between interventions which are clearly perceived by the market and those which are only guessed at by FX traders. This distinction between two types of secret intervention (pure secret interventions and detected secret interventions) is an important contribution of this work, and contrasts with previous empirical studies.

Table 2: Examples of news reports used to identify detected secret interventions

\begin{tabular}{|c|c|c|}
\hline Date & Sources & Relevant text of the news report (classified as rumors) \\
\hline March 3, 1995 & Dow Jones & $\begin{array}{l}\text { "Though traders couldn't confirm the BoJ intervention, several said } \\
\text { they were positive the central bank stepped in the market stealthily at } \\
\text { regular intervals Friday between } 95.40-.50 \text { yen" }\end{array}$ \\
\hline February 22, 1996 & Reuters & $\begin{array}{l}\text { "U.S. currency traders remain watchful of central bank intervention to support } \\
\text { the U.S. dollar. After the Bank of Japan was believed to have been in } \\
\text { the market buying U.S. dollars Thursday" }\end{array}$ \\
\hline May 21,2003 & Reuters & "Asia Forex -2: Dlr underpinned by rumored covert MoF bids" \\
\hline October 29, 2003 & Dow Jones & $\begin{array}{l}\text { "In early New York trading. the dollar was trading at } 108.04 \text { yen. slightly } \\
\text { above its latest three-year low below } 107.90 \text { yen. with traders suspecting the } \\
\text { Bank of Japan might be quietly preventing further losses. Market } \\
\text { sources said the central bank may have been selling yen for dollars in } \\
\text { Asian trade but this could not be confirmed" }\end{array}$ \\
\hline October 29, 2003 & Dow Jones & $\begin{array}{l}\text { "Dollar climbs amid suspicion of BoJ Intervention /NEW YORK - The } \\
\text { dollar edged higher against its major rivals consolidating gains as suspicions } \\
\text { intensified that the Bank of Japan had intervened covertly to weaken } \\
\text { the yen" }\end{array}$ \\
\hline November 18, 2003 & Dow Jones & $\begin{array}{l}\text { "Several traders suspected the Bank of Japan acting on behalf of Japan's } \\
\text { Ministry of Finance was intervening covertly by selling yen around } 108 \text { yen } \\
\text { to keep the dollar from breaking into a free fall" }\end{array}$ \\
\hline February 20, 2004 & Reuters & $\begin{array}{l}\text { "It also broke above Y109 Friday for the first time since early December, helped } \\
\text { by what traders have cited as covert dollar-buying by the Bank of Japan } \\
\text { through agent banks" }\end{array}$ \\
\hline
\end{tabular}

Note: Reports in this table clearly indicate that the market does not know clearly whether an intervention was taking place in the market, whereas official data ex post shows that it was the case.

\footnotetext{
${ }^{14}$ Newsreports with a high degree of uncertainty can be easily recognized as they generally contain words such as "likely", "believed", "may have/think", "rumor", "unconfirmed", "suspected/speculation" and "covert".

${ }^{15}$ We exclude reports of interventions occurring on days when no official interventions were in fact carried out (i.e. when the market mistakenly believed that the central bank had intervened). Such reports are called false reports.
} 


\subsubsection{Summing up}

Table 3 shows the number of official interventions (as indicated by the Japanese Ministry of Finance itself) that were conducted over the period of interest. The methodology described in the previous section allows us to determine that 212 of the 343 official interventions were public (i.e. clear reports were found suggesting that market participants knew an intervention had been conducted) while 131 were secret (i.e. either no report indicating that an intervention had been conducted could be found or the existing report did not exhibit a sufficient degree of clarity). Among these secret operations, the Japanese authorities actually managed to conceal its operations on 75 occasions and failed 56 times. ${ }^{16}$

Table 3: Type of BoJ intervention 1991-2004

\begin{tabular}{|c|c|c|c|c|}
\hline Trading days & Official & Reported & \multicolumn{2}{|c|}{ Secret } \\
\hline & & Public & Undetected & Detected \\
\hline 3498 & 343 & 212 & 75 & 56 \\
\hline
\end{tabular}

\subsection{Explanatory variables}

We turn now to the choice and measurement of the explanatory variables. These are summarized in Table 4 and discussed in more detail in the following sections.

\subsubsection{Empirical counterparts of the intervention decision, $W$}

The extensive literature on why central banks use FX interventions has been reviewed in several recent surveys (e.g. Sarno and Taylor, 2001). Specific studies involving the BoJ include Ito (2003), Ito and Yabu (2004) and Bernal (2006), among many others.

\section{Exchange rate variation}

Like other central banks, the Bank of Japan is reported to lean against the wind (i.e. to try to reverse previous undesirable exchange rate changes). Ito (2003) observed that the BoJ intervened to stabilize the spot exchange rate changes with respect to short-, medium- and long-term deviations. To capture this behavior, we use past exchange rate variations observed at one-day, one-month and one-year frequencies.

\footnotetext{
${ }^{16}$ Galati and Melick, 1999 also extract perceived interventions of the BoJ over the 1993-1996 period. They use reports extracted from the Nexis-Lexis database.A cross-check between our findings and the ones of Galati and Melick, 1999 shows that both databases were quite effective in capturing the reported interventions. Over this period, only one intervention (on the 3rd of November 2004) classified as secret in our data was reported by the Lexis-Nexis database. Conversely, 3 operations that were considered unreported in the Lexis-Nexis database were classified as public interventions in our dataset. We are grateful to Gabriele Galati for sharing his database with us.
} 
Table 4: Empirical measures of the explanatory variables $(W, Z$ and $X)$ for central bank's interventions

\begin{tabular}{|c|c|}
\hline Variables & Definition \\
\hline \multicolumn{2}{|l|}{$W$ (intervention decision) } \\
\hline dev short & Absolute level of short-term deviation in percentage \\
\hline dev medium & Absolute level of medium-term deviation in percentage \\
\hline dev long & Absolute level of long-term deviation in percentage \\
\hline mis & Absolute level of misalignment in percentage \\
\hline misdum & $\begin{array}{l}1 \text { if there is a large deviation between the current exchange rate and its funda- } \\
\text { mental value }\end{array}$ \\
\hline statement & $\begin{array}{l}1 \text { if authorities made a statement expressing some discomfort with the exchange } \\
\text { rate or confirming/discussing the intervention on the day of the operation }\end{array}$ \\
\hline intervention $_{t-1}$ & 1 if there was an official intervention the day before \\
\hline$R V_{t-1}$ & Exchange rate realized volatility of preceding day, estimated at the end of the day \\
\hline \multicolumn{2}{|l|}{$Z$ (choice of secrecy) } \\
\hline leaning & 1 if the intervention tries to reverse recent exchange rate trend \\
\hline previous reported success & 1 if the last detected intervention was a success \\
\hline inconsist & $\begin{array}{l}1 \text { if the intervention direction is inconsistent with the reduction of the exchange } \\
\text { rate misalignment }\end{array}$ \\
\hline sum statement & $\begin{array}{l}\text { Number of verbal interventions from the authorities signaling a discomfort with } \\
\text { the exchange rate in the } 5 \text { days before the intervention }\end{array}$ \\
\hline \multicolumn{2}{|l|}{$X($ detection process $)$} \\
\hline amount & Amount invested in the daily intervention \\
\hline coord & 1 if intervention is concerted \\
\hline cluster & 1 if there is at least one detected intervention over the last 5 preceding days \\
\hline success & 1 if the intervention moves the exchange rate in the desired direction \\
\hline
\end{tabular}

Three variables, denoted dev short, dev medium and dev long, were then built to reflect the size of the (absolute) deviation of the current exchange rate from the previous day, the past one-month moving average, and the past one-year moving average. The variables capture the dynamic of the exchange rate around some implicit short-, medium- and long-term target respectively (see Almekinders and Eijffinger, 1996; Ito, 2003 and Ito and Yabu, 2004). Since interventions are supposed to influence the exchange rate level, these variables may suffer from simultaneity problems if the contemporaneous exchange rate level $s_{t}$ is used. Therefore, our measure is corrected by using the one-day lagged JPY/USD rate $\left(s_{t-1}\right)$ instead of the current rate. From an economic point of view, this shift is meaningful, since the central bank should presumably face administrative or political costs before implementing an intervention (Almekinders, 1995 and Ito and Yabu, 2004), so that a small delay between the decision to intervene (based on the exchange rate deviation, for example) and its implementation may be expected. In practice the variables are computed as follows:

$$
\text { dev horizon } i, t=100 \times\left|s_{t-1}-\sum_{j=2}^{i} s_{t-j}\right|
$$

where $s_{t}$ denotes the log of the JPY/USD rate at the close of the New York market $(21 \mathrm{GMT}+1)$, and $i$ is the time horizon in trading days $(i=2,21$ and 260$)$. 


\section{Exchange rate misalignment}

FX interventions are also supposed to reduce the deviations of the exchange rate with respect to some fundamental value (i.e. to minimize the degree of currency misalignment). The BoJ is charged with this specific goal. ${ }^{17}$ We used a specific measure of the misalignment to test whether the intervention activity responded to deviations of the exchange rate from its fundamental value.

The degree of misalignment (denoted mis) of the exchange rate level is measured by computing the size of the (absolute) deviation of the current rate (more precisely $s_{t-1}$ to control for simultaneity issues) from the equilibrium exchange rate. For the equilibrium rate we used that computed by BénassyQuéré et al. (2004) to reflect the level needed for a global equilibrium between the G-20 economies. The equilibrium level of the JPY/USD exchange rate is computed annually, so, to obtain daily values we interpolated between the two end-of -year values.However, this variable can suffer from non-stationarity. ${ }^{18}$ To allow for this, as an alternative used in a robustness check analysis, we constructed another measure of misalignment (denoted misdum) which is a dummy variable that takes the value 1 on days of high misalignment and 0 otherwise. We consider the $10 \%$ of days with the highest positive misalignment and the $10 \%$ of days with the highest negative misalignment as high misalignment.

\section{Volatility}

Although there is no explicit volatility target, the goal of "calming disorderly markets" is frequently used by officials to justify interventions. We included a measure of exchange rate volatility to test to what extent this actually influences the authorities' behavior.

As suggested by Andersen et al. (2002), we use the realized volatility (denoted by $R V_{t}$ ). This is a consistent estimate of the integrated (latent) volatility and is less subject to the issue of generated regressors (Pagan, 1984) than parametric estimates of the volatility (such as GARCH estimates). In practice the realized volatility for day $t$ is computed by sampling the intra-daily data at a high frequency and cumulating the square products of the relevant returns over a specific horizon (here a day). If $m$ is the fixed sampling frequency ( $m=288$ for 5 -minute intervals over 24 hours), the daily measure of the realized volatility is

$$
R V_{t}=\sum_{j=0}^{m-1}\left(r_{t, j}\right)^{2}
$$

Since interventions are also known to raise volatility, we used the one-day lagged realized volatility.

\footnotetext{
${ }^{17}$ The Foreign Exchange and Foreign Trade Law stipulates that the "Minister of Finance shall endeavor to stabilize the external value of the yen through foreign exchange trading and other measures" (Article 7, Section 3). (http://www.boj. or.jp/en/type/exp/faqkainy.htm)

${ }^{18}$ The mis variable is obviously non-stationary if there is no tendency for the exchange rate to revert to the equilibrium value. It should also be stressed that, to the best of our knowledge, the consequences of non-stationarity in limiteddependent variable models (such as the nested logit model) has received very little attention. Therefore, the alternative measure of the exchange rate misalignment is only included in the robustness analysis.
} 
This should be a good approximation, given the volatility clustering usually observed for exchange rates (Andersen et al., 2001).

\section{Statements}

Statements made by Japanese officials and representatives of the BoJ are also included in our model as they can interact with actual interventions. The role of statements has been studied by several authors including Fatum and Hutchinson (2002) and Jansen and de Haan (2005). Basically, official statements can be regarded as a complementary or substitute tools for FX operations. Fratzscher (2004) argues that oral interventions can be an alternative to physical sales or purchase of foreign currency. Policymakers can try to regulate their currency by expressing to the market their views regarding the exchange rate value or the usefulness of interventions. Beine et al. (2004) nevertheless also found support for a complementary role for contemporaneous statements. By clarifying the goal of interventions and the context in which those operations were conducted, monetary authorities can magnify the signal conveyed by actual operations. More generally, however, Bernal and Gnabo (2006) established that only in extreme cases are financial operations accompanied by contemporaneous statements.

Two types of statements are included in our analysis: (i) those giving pieces of information about the future exchange rate policy (i.e. statements informing the market of the authorities' view of exchange rates level or their volatility); and (ii) those clearly indicating the possibility of a future intervention which may be seen as threats to intervene (see Fatum and Hutchinson, 2002). A dummy variable (statement) is used to indicate whether such statements occurred on a given trading day. We also built another variable (called sum statement) to capture the number of official statements issued during the five days preceding an intervention operation. This variable may be seen as an indicator of the state of the recent transparency policy.

\section{Lagged intervention}

Finally, to capture the time dependency generally observed for actual central bank interventions, the first lag of an intervention is included (intervention ${ }_{t-1}$ ). This captures the clustering nature of central bank interventions over time. The literature usually explains this feature by the existence of "political costs" associated with the intervention decision process (Almekinders, 1995 and Ito and Yabu, 2004). As documented by Ito (2003) and Gnabo and Lecourt (2005), this approach has been widely used by Japanese authorities during the last decade. As a matter of fact, the likelihood of an intervention by the BoJ when there had been an intervention on the previous day was over 60\% between 1991 and 2004 . 


\subsubsection{Empirical counterparts of the choice of secrecy, $Z$}

The decision to intervene secretly rather than publicly has been rationalized by a few authors. In their empirical paper, Beine and Bernal (2006) review various arguments in favor of secrecy. In this paper, we have basically used the same variables, and we invite the interested reader to refer to Beine and Bernal (2006) for additional discussion of their rationale. Note that in his updated survey, Neely (2006) investigates the same underlying reasons for opting for secrecy.

\section{Inconsistent interventions}

An inconsistent intervention is an operation that attempts to move the exchange rate in the "wrong" direction. The concept of wrong direction is of course not a natural one. For instance, inconsistency might occur when the central bank targets a different value from the fundamental equilibrium exchange rate (Vitale, 1999). These arguments have been developed within the microstructure approach to exchange rates that relies on the twin assumptions of agents' heterogeneity and information asymmetry. In that framework, the secrecy of order flows allows trading by the central bank to be indistinguishable from private trading, and the central bank may then target an exchange rate that differs from the fundamental one (Lyons, 2001, Evans and Lyons, 2001).

The inconsist variable was introduced to capture the inconsistency of an intervention. It is a dummy built by comparing the sign of the misalignment of the exchange rate with the sign of the official intervention (sale or purchase), and takes the value 1 when the BoJ intervenes in the opposite direction to that needed to reduce the misalignment (e.g. when the BoJ buys JPY when it is overvalued or sells JPY when it is undervalued) and 0 otherwise. As an alternative, we consider the interaction between the degree of misalignment and the inconsistency dummy. This variable (denoted inconsist $\times$ mis) aims to give more weight to inconsistent policies occurring during periods of large over- or undervaluation of the exchange rate.

\section{Previous success of interventions}

The previous success of FX operations can be seen as a measure of the credibility of a central bank. As emphasized by Dominguez and Frankel (1993) and Chiu (2003), a low level of credibility or a previous failure to move the market in the desired direction might persuade the central bank to opt for secrecy. Indeed, using secret interventions would allow the central bank to avoid a further deterioration of its perceived ability to achieve a specific goal or to avoid significant increases of the exchange rate volatility. Interestingly, central bankers themselves seem to think that the failure of previous interventions tends to favor the use of secret operations (Neely, 2006). Alternatively, in the case of a previous reported success, and when the current context appears less favorable, the central bank might also want to intervene secretly to preserve its credibility. Therefore, credibility, as measured by the performance of previous 
interventions, exerts an ambiguous theoretical influence on the use of secret operations. ${ }^{19}$

To assess the impact of the effectiveness of past interventions, we built a variable denoted previous reported success that takes the value 1 if the last detected intervention succeeded in moving the exchange rate in the desired direction. It is worth noting that we restricted our analysis to detected interventions. Traders might well be unaware of (undetected) interventions conducted during the past few days. Obviously, the failure of these operations would not jeopardize the central bank's credibility and, so, on this theory, would not influence the strategy for future interventions.

\section{Leaning-against-the-wind}

In the noise-trading channel theory, a secret intervention can mitigate bandwagon effects (Dominguez and Frankel, 1993). Indeed, the secrecy of these order flows and the resulting increase in volatility might restore a two-way risk and lead market participants to consider exchange rate fluctuations as purely endogenous to the market (Hung, 1997). Secrecy ensures then that the intervention works through a pure portfolio effect, and that market participants will not react to the mere fact that the central bank is leaning against the wind (perverse signaling effect). In this context, leaning-against-the-wind behavior can encourage secret operations.

These noise-trading arguments (Hung, 1997) ) were considered in our analysis by taking account of whether the central bank has exhibited leaning-against-the-wind behavior. A variable (denoted leaning) was built by comparing the sign of the intervention with the average sign of the last five daily exchange rate returns. It takes the value 1 when the intervention goes in the opposite direction to the recent exchange rate trend and 0 otherwise. We find that about two thirds of Japanese interventions were of a leaning-against-the wind type.

\subsubsection{Empirical counterparts of the detection process, $X$}

Several variables have already been identified by Beine and Bernal (2006) as major determinants of the ways in which FX traders detect central bank operations. Nevertheless, as already discussed, that study relies on the validity of an ex ante decomposition between $Z$ and $X$. One of the purposes of the nested logit approach adopted here is to assess the robustness of the previous findings by decomposing the observed outcomes by decision levels. Beine and Lecourt (2004)'s preliminary analysis also provides some clues as to which variables influence the probability of detecting the presence of the central bank in the market. The relevance of these variables has been confirmed by Neely (2006)'s recent survey of central bankers beliefs (see in particular Table 3 of his analysis). These determinants mainly concern features of central bank interventions. However, they also deal with market conditions.

\footnotetext{
${ }^{19}$ More generally, central bank practices suggest that the performance of past interventions might influence a central bank's decision about its intervention policy. Results of the survey conducted by Neely (2001) indicate that a central bank's trading is influenced by the response of exchange rates to its previous interventions.
} 


\section{Coordinated interventions}

Coordination between two or more central banks is expected to increase the visibility of any operation. As documented by Beine and Lecourt (2004) the proportion of unreported concerted interventions is low. This is consistent with the fact that coordination is expected to increase the probability of detection by most central banks (Neely, 2006). ${ }^{20}$

A dummy variable (denoted coord), taking the value 1 if the intervention is coordinated and 0 otherwise, was introduced. An intervention is considered coordinated if two or more central banks intervened on the same day in the same market and in the same direction. In this paper, as our focus is on the JPY/USD market, we only consider coordination between the BoJ and the Fed. We use the official data of the Fed to identify these days.

\section{Amount invested in daily interventions}

The size of an intervention is expected to influence the extent to which traders can detect the presence of the central bank. Indeed, central bankers consider the size of their interventions to be one of the most prominent features influencing the detection process (Neely, 2006). The daily amount is therefore expected to influence the rate of detection of interventions by the market positively. In theory, the daily size of interventions not only reflects the size of the order flows given by the central bank but also their number. However, this information is unavailable for most central bank operations, including those of the BoJ. Therefore, in this study, the variable amount only reflects the total daily amount of an intervention in billions of JPY.

\section{Cluster of interventions}

Detected interventions in the days preceding an intervention should raise traders' awareness of the presence of the central bank in the market. Empirical reaction functions (Almekinders, 1995; Ito, 2003 and Ito and Yabu, 2004) suggest that the probability of intervening is higher when the central bank has intervened in the previous few days. This fits with the cluster behavior of central bank interventions that has been documented in numerous studies. The existence of recent previous interventions is also mentioned by central bankers as a key variable for the detection of FX operations (Neely, 2006). We built a variable (cluster) that takes the value 1 if there was at least one perceived intervention during the five days preceding an intervention operation.

\footnotetext{
${ }^{20}$ It could also be argued that an agreement between several central banks to intervene at the same time reflects their willingness to send a strong signal to the market. The use of secret interventions would be inconsistent with such an international agreement.
} 


\section{Success}

Finally, the success of an intervention can also influence the extent to which this intervention is detected. Dominguez (2003) provides a stunning example of this by looking at the effect of the Fed's intervention on May 31, 1995. The first order by the Fed resulted in the DEM/USD rate jumping by more than $2 \%$, drawing the attention of traders and triggering newswire reports. Subsequent trades by the Fed on that day were therefore easily detected.

In this study a given intervention is considered successful if it moved the exchange rate in the desired direction. Although restrictive, this definition is consistent with the main objective of the BoJ over our period of investigation. We compared the sign of the exchange rate return between day $t-1$ and day $t$ with the sign of the intervention occurring on date $t$. Variable success takes the value 1 if a purchase (sale) of yen led to an appreciation (depreciation) of the yen. ${ }^{21}$

\section{$6 \quad$ Econometric results}

In order to assess the relevance of the nested logit framework described in the previous sections, we estimated a multinomial logit model along with the nested logit itself.The significance of inclusve values of the nested logit model as well as the likelihood ratio tests between the two models can be used as a useful check of the relevance of the nested logit structure. The estimates of both models are shown in Table 5. Column (1) reports the estimates of the multinomial logit while Columns (2), (3) and (4) give estimates of the full, semi-parsimonious and parsimonious nested logit models. Some robustness checks were also conducted and these are reported in Table 6. First, we used a dummy variable $($ misdum) to capture large degrees of misalignment as a way of accounting for the non-stationarity of mis (Column (1)). Second, an alternative measure of the inconsistency of the exchange rate policy $($ inconsist $\times$ mis) was introduced as a determinant of the use of secret interventions so as to give more weight to large deviations of the exchange rate from the equilibrium level (Column (2)). Finally, the contemporaneous and past official statements were introduced into the second level instead of the first one, to capture the role of the communication policy (Columns (3) and (4)).

The results definitely support the nested structure of the model. All the Small-Hsiao tests reject the validity of the IIA assumption, indicating some similarities among the alternatives. ${ }^{22}$ Moreover, the nested logit model outperforms the multinomial logit, as suggested by the significance of the inclusive values $\left(\Theta_{1}\right.$ and $\left.\Theta_{2}\right)$ as well as by the large increase in the log-likelihood. ${ }^{23}$ The idea of interdependent

\footnotetext{
${ }^{21}$ This variable uses a contemporaneous version of the success of a FX operation. This contrasts with the previous reported success variable used to explain the choice of secrecy.

${ }^{22}$ These tests were conducted on several estimated models. We first tested the IIA assumption on the full model involving all three levels. Then, we considered sub-models with either the first or the last two levels. In most cases, the p-values led to a clear rejection of the IIA hypothesis. These results are not reported here for the sake of brevity but are available upon request.

${ }^{23}$ It is noteworthy that both $\Theta_{1}$ and $\Theta_{2}$ are greater than 1. According to McFadden (1984) they should be less than 1 for the nested logit to be consistent with the random utility maximization program which usually underlies such models.
} 
sequential steps in the intervention procedure rather than independent processes is thus supported. Importantly, the nested logit framework implies that some of the estimates of the multinomial logit might be subject to specification bias. This is important since for a (small) subset of variables, opposite signs between the two models are obtained, stressing the importance of our new approach for policy evaluation.

\section{First level : intervention reaction function}

For the sake of interpretation, it is important to mention that the underlying utility of the first level is related to the non-intervention outcome. In other words, positive (or negative) coefficients imply that an increase in the explanatory variable tends to decrease (increase) the probability of intervention.

Our results indicate that an increase in the misalignment of the exchange rate tends to induce the BoJ to be more active on the FX market (mis has a significant negative coefficient in Tables 5 and 6 ). This result does not seem to be driven by the non-stationarity of mis as we obtain similar results by using a dummy variable (misdum) to capture large currency misalignments (see the upper panel of Table 6). In contrast, our estimates do not support the idea that the BoJ reacts systematically either to variations of the exchange rate from past values (dev short, dev medium and dev long are not significant) nor to exchange rate volatility $\left(R V_{t-1}\right.$ is significant in the multinomial logit but not when a nested structure is imposed). This result is consistent with Ito (2006)'s claim that, on average, central banks in general and the BoJ in particular do not worry about volatility. This is also consistent with Galati et al. (2006)'s results.

Interestingly, official statements (statement) by the central bank are found to be positively related to the probability of intervention. This supports the view that this instrument can be used as a complement to central bank operations (Beine et al., 2004). That is, statements accompanying interventions help to clarify the message embodied in these operations. By informing the market about the authorities' view of exchange rate levels or volatility, or by indicating the possibility of a future intervention, statements permit the BoJ to amplify the results of its operations.

Not surprisingly, past interventions (intervention in-1 $_{\text {) }}$ are found to be one of the main determinants of the BoJ reaction function. This finding is fully in line with most other studies and is consistent with previous research describing the administrative and political costs of interventions (Ito and Yabu, 2004) and indicating that once the monetary authorities reach agreement on what threshold to defend, they may conduct several interventions in a row. As subsequent interventions do not require any further political bargaining, they are easier (and less costly) to implement.

However, the model presented in this paper is not entirely a random utility maximization one. While the upper levels clearly describe the behavior of an optimizing central bank, this is not true for the sub-nest containing the "detected secret" and "pure secret" interventions, which are exclusively related to the perception of the market. Therefore, the fact that $\Theta_{1}$ and $\Theta_{2}$ are both greater than 1 should not be of major concern. 
Table 5: Multinomial logit and Nested logit estimation

\begin{tabular}{|c|c|c|c|c|}
\hline Variables & $(1)$ & $(2)$ & $(3)$ & $(4)$ \\
\hline \multicolumn{5}{|c|}{ Top variables : intervention decision (Probability of non intervention) } \\
\hline \multirow[t]{2}{*}{ Constant } & $5.225^{* * *}$ & $1.556^{* * *}$ & $1.543^{* * *}$ & $1.546 * * *$ \\
\hline & {$[0.236]$} & {$[0.089]$} & {$[0.086]$} & {$[0.086]$} \\
\hline \multirow[t]{2}{*}{ dev short } & -0.128 & -0.009 & - & - \\
\hline & [0.188] & [0.034] & & \\
\hline \multirow[t]{2}{*}{ dev medium } & -0.106 & 0.005 & - & - \\
\hline & {$[0.074]$} & {$[0.015]$} & & \\
\hline \multirow[t]{2}{*}{ dev long } & -0.019 & -0.005 & - & - \\
\hline & [0.025] & {$[0.005]$} & & \\
\hline \multirow[t]{2}{*}{ mis } & -0.016 & $-0.006^{* * *}$ & $-0.006^{* * *}$ & $-0.006^{* * *}$ \\
\hline & [0.010] & [0.002] & [0.002] & [0.002] \\
\hline \multirow[t]{2}{*}{ statement } & $-0.735 * * *$ & $-0.097 * *$ & $-0.100 * *$ & $-0.097^{* *}$ \\
\hline & [0.186] & [0.039] & [0.039] & [0.039] \\
\hline \multirow[t]{2}{*}{ intervention $_{t-1}$} & $-2.827^{* * *}$ & $-0.349^{* * *}$ & $-0.349 * * *$ & $-0.345^{* * *}$ \\
\hline & [0.186] & [0.050] & [0.049] & [0.048] \\
\hline \multirow[t]{2}{*}{$\mathrm{RV}_{t-1}$} & $0.478^{* * *}$ & 0.016 & 0.009 & - \\
\hline & [0.181] & {$[0.028]$} & {$[0.022]$} & \\
\hline \multicolumn{5}{|c|}{ Mid variables : secrecy strategy (Probability of public intervention) } \\
\hline \multirow[t]{2}{*}{ leaning } & $3.642^{* * *}$ & $1.397^{* * *}$ & $1.404^{* * *}$ & $1.403^{* * *}$ \\
\hline & {$[0.272]$} & {$[0.082]$} & {$[0.081]$} & {$[0.081]$} \\
\hline \multirow[t]{2}{*}{ previous reported success } & $3.532 * * *$ & $1.421^{* * *}$ & $1.411^{* * *}$ & $1.406^{* * *}$ \\
\hline & {$[0.363]$} & {$[0.108]$} & {$[0.107]$} & {$[0.106]$} \\
\hline \multirow[t]{2}{*}{ inconsist } & $-0.882^{* * *}$ & $0.454^{* * *}$ & $0.433^{* * *}$ & $0.439 * * *$ \\
\hline & [0.345] & [0.163] & {$[0.155]$} & {$[0.156]$} \\
\hline \multicolumn{5}{|c|}{ Bottom variables : detection process (Probability of detection) } \\
\hline \multirow[t]{2}{*}{ amount } & $0.010^{* * *}$ & $0.007^{* * *}$ & $0.007^{* * *}$ & $0.007^{* * *}$ \\
\hline & {$[0.001]$} & {$[0.001]$} & {$[0.001]$} & {$[0.001]$} \\
\hline \multirow[t]{2}{*}{ coord } & $5.964^{* * *}$ & $2.369^{* * *}$ & $2.363^{* * *}$ & $2.362^{* * *}$ \\
\hline & {$[1.650]$} & {$[0.856]$} & {$[0.854]$} & {$[0.854]$} \\
\hline \multirow[t]{2}{*}{ success } & $2.359^{* * *}$ & $1.515^{* * *}$ & $1.509 * * *$ & $1.511^{* * *}$ \\
\hline & {$[0.409]$} & {$[0.217]$} & {$[0.215]$} & {$[0.215]$} \\
\hline \multirow[t]{2}{*}{ cluster } & -0.364 & $0.443^{* * *}$ & $0.444^{* * *}$ & $0.442^{* * *}$ \\
\hline & {$[0.402]$} & {$[0.162]$} & {$[0.160]$} & {$[0.161]$} \\
\hline \multicolumn{5}{|l|}{ Inclusive values } \\
\hline \multirow[t]{2}{*}{$\Theta_{1}$} & - & $3.507 * * *$ & $3.466^{* * *}$ & $3.472^{* * *}$ \\
\hline & & {$[0.443]$} & {$[0.422]$} & {$[0.425]$} \\
\hline \multirow[t]{2}{*}{$\Theta_{2}$} & - & $2.125^{* * *}$ & $2.137^{* * *}$ & $2.136^{* * *}$ \\
\hline & & {$[.246]$} & [0.245] & {$[0.245]$} \\
\hline Log Likelikood & -705.232 & -505.196 & -505.769 & -505.871 \\
\hline
\end{tabular}

Note: Column (1) gives the estimates of the multinomial logit specification, while columns (2) to (4) report the estimates of the full, semi-parsimonious and parsimonious nested logit models. The $10 \%, 5 \%$ and $1 \%$ levels of significance are indicated by $*, * *$ and $* * *$ respectively. 
Table 6: Nested logit estimation: Robustness analysis

\begin{tabular}{|c|c|c|c|c|}
\hline Variables & $(1)$ & $(2)$ & $(3)$ & $(4)$ \\
\hline \multicolumn{5}{|c|}{ Top variables : intervention decision (Probability of non intervention) } \\
\hline \multirow[t]{2}{*}{ Constant } & $1.467^{* * *}$ & $1.525^{* * *}$ & $1.460^{* * *}$ & $1.403^{* * *}$ \\
\hline & {$[0.074]$} & {$[0.082]$} & {$[0.078]$} & {$[0.074]$} \\
\hline \multirow[t]{2}{*}{ misdum } & $-0.087^{* *}$ & - & - & - \\
\hline & {$[0.039]$} & & & \\
\hline \multirow[t]{2}{*}{ mis } & - & $-0.005^{* *}$ & $-0.006^{* * *}$ & $-0.006 * * *$ \\
\hline & & {$[0.002]$} & [0.002] & [0.002] \\
\hline \multirow[t]{2}{*}{ statement } & $-0.094^{* *}$ & $-0.092^{* *}$ & - & - \\
\hline & {$[0.039]$} & {$[0.039]$} & & \\
\hline \multirow{2}{*}{ intervention $_{t-1}$} & $-0.354^{* * *}$ & $-0.356^{* * *}$ & $-0.320^{* * *}$ & $-0.265^{* * *}$ \\
\hline & [0.049] & [0.049] & [0.043] & [0.040] \\
\hline \multicolumn{5}{|c|}{ Mid Variables: secrecy strategy (Probability of public intervention) } \\
\hline \multirow[t]{2}{*}{ leaning } & $1.423^{* * *}$ & $1.471^{* * *}$ & $1.203^{* * *}$ & $1.142^{* * *}$ \\
\hline & {$[0.082]$} & {$[0.085]$} & {$[0.071]$} & {$[0.068]$} \\
\hline \multirow[t]{2}{*}{ previous reported success } & $1.441^{* * *}$ & $1.413^{* * *}$ & $1.295^{* * *}$ & $1.231^{* * *}$ \\
\hline & [0.108] & {$[0.107]$} & [0.098] & [0.093] \\
\hline \multirow[t]{2}{*}{ inconsist } & $0.396^{* * *}$ & - & $0.480^{* * *}$ & $0.453^{* * *}$ \\
\hline & {$[0.153]$} & & {$[0.145]$} & {$[0.116]$} \\
\hline \multirow[t]{2}{*}{ inconsist $\times$ mis } & - & $0.018^{*}$ & - & - \\
\hline & & {$[0.010]$} & & \\
\hline \multirow[t]{2}{*}{ statement } & - & - & $0.418^{* * *}$ & - \\
\hline & & & {$[0.062]$} & \\
\hline \multirow[t]{2}{*}{ sum statement } & - & - & - & $0.131^{* * *}$ \\
\hline & & & & {$[0.015]$} \\
\hline \multicolumn{5}{|c|}{ Bottom variables: detection process (Probability of detection) } \\
\hline \multirow[t]{2}{*}{ amount } & $0.007 * * *$ & $0.007^{* * *}$ & $0.007^{* * *}$ & $0.007^{* * *}$ \\
\hline & [0.001] & [0.001] & [0.001] & [0.001] \\
\hline \multirow[t]{2}{*}{ coord } & $2.380^{* * *}$ & $2.344^{* * *}$ & $2.102^{* * *}$ & $2.103^{* * *}$ \\
\hline & {$[0.856]$} & [0.852] & {$[0.804]$} & {$[0.775]$} \\
\hline \multirow[t]{2}{*}{ success } & $1.497^{* * *}$ & $1.450^{* * *}$ & $1.517^{* * *}$ & $1.528^{* * *}$ \\
\hline & {$[0.216]$} & [0.199] & {$[0.220]$} & {$[0.218]$} \\
\hline \multirow[t]{2}{*}{ cluster } & $0.461^{* *}$ & $0.491 * * *$ & $0.448^{* * *}$ & $0.464^{* * *}$ \\
\hline & [0.159 ] & {$[0.153]$} & {$[0.150]$} & [0.139] \\
\hline \multicolumn{5}{|l|}{ Inclusive values } \\
\hline \multirow[t]{2}{*}{$\Theta_{1}$} & $3.457^{* * *}$ & $3.203^{* * *}$ & $3.564^{* * *}$ & $3.688^{* * *}$ \\
\hline & [0.420] & {$[0.347]$} & [0.443] & [0.432] \\
\hline \multirow[t]{2}{*}{$\Theta_{2}$} & $2.138^{* * *}$ & $2.223^{* * *}$ & $2.397 * * *$ & $2.536^{* * *}$ \\
\hline & {$[0.244]$} & {$[0.244]$} & {$[0.271]$} & {$[0.283]$} \\
\hline Log Likelikood & -507.968 & -511.452 & -488.515 & -485.675 \\
\hline
\end{tabular}

Note: Estimates in this table correspond to robustness tests of the parsimonious nested logit model. Column (1) considers a dummy version (misdum) of the misalignment variable. Column (2) incorporates a continuous version of the variable measuring the inconsistency of an intervention with respect to the objective of reducing the misalignment (inconsist $\times$ mis). Columns (3) and (4) include the variables statement and sum statement respectively at the second level. The 10\%, $5 \%$ and $1 \%$ levels of significance are indicated by $*, * *$ and $* * *$ respectively. 


\section{Second level: secrecy puzzle}

As for the first level, it is important to notice that the underlying utility of the second level depends upon the decision to intervene publicly. That is, positive (or negative) coefficients imply that an increase in the explanatory variable tends to increase (decrease) the probability of using a public intervention (i.e. an intervention which the central bank wants market participants to know about) and so to decrease (increase) the probability of using a secret intervention (i.e. an intervention the central bank wants to hide from market participants). The estimates of the parameters in the second nest are directly linked to the secrecy puzzle in the sense that they give some information about the determinants of the choice of secrecy.

Interestingly, the three variables considered as determinants of the choice of secrecy all turn out to be significant. Little evidence is revealed about the noise-trading channel as a way of explaining the use of secret interventions by the BoJ. Indeed, while that argument would suggest that a leaning-againstthe-wind context would favor the use of secret interventions, we find the opposite effect (leaning has a significant positive coefficient). This means that when the BoJ conducts interventions to reverse a recent trend, it tends to use public rather than secret interventions. Of course, the way the noise-trading approach is tested in this model is quite unusual. Since central banks do not often release information about their intervention strategies, indirect evidence has to be used to assess the presence of such a channel. Further research is clearly needed before drawing more conclusions. Nevertheless, our rejection of a noise-trading strategy is consistent with Neely (2006)'s findings: on average, central bankers do not seem to believe that leaning-against-the-wind favors the use of secret interventions.

Our results on the inconsistency of the exchange rate policy and the fundamental equilibrium exchange rate differ from those obtained by Beine and Bernal (2006). Beine and Bernal (2006) found that when the direction of an intervention is inconsistent with a reduction in the degree of misalignment, the BoJ tended to favor the use of secret interventions. However our nested logit approach gives the opposite result (inconsist has a significant positive coefficient). The findings of the multinomial logit (column (1) of Table 5), suggest that the previous result might be due to a failure to decompose the decision process into sequential interdependent steps. Moreover Beine and Bernal (2006)'s results rely on the validity of an ex ante identification between the determinants of secrecy and those favoring the detection of interventions. The present study, by achieving a clear distinction between the different decision levels, allows the identification of the relevant determinants to come directly from the theory. Furthermore, when large deviations of the exchange rate from the equilibrium value are taken into account, the impact of inconsistent policies is much less significant (see variable inconsist $\times$ mis in Table 6). This result emphasizes the importance of the nested logit structure that allows a clear distinction between the decision to use secret intervention and the detection process conducted by FX traders to be made. This distinction is impossible in a multinomial logit framework or in a simple logit model of detected and 
undetected operations (as used by Beine and Bernal, 2006). The fact that inconsistency of intervention policy leads to the use of public interventions is consistent with the hypothesis of multiple equilibria and with the view that interventions are used in an attempt to coordinate market participants' expectations on an exchange rate level different from the prevailing one. In this context, highly visible operations can be used as a device to alter market expectations.

Our results also show that previous success tends to favor the use of public interventions (previous reported success has a significant positive coefficient). This result is in line with the idea that secrecy may be used by central banks when their credibility has been called into question by several recent failures in their intervention policy (Chiu, 2003). Central bankers' opinions support this hypothesis moderately well (Neely, 2006).

When statements are introduced at the second level (Columns (3) and (4) in Table 6), a significant positive correlation between statements and open interventions is established. This result holds both for contemporaneous statements and for statements issued in the days preceding the intervention, and indicates that when the BoJ conducts a more transparent policy, it tends to use more public interventions. ${ }^{24}$

\section{Third level: detection of interventions}

The third level results concern the detection of secret interventions. A positive (or negative) coefficient indicates that an increase in the independent variable increases (decreases) the probability of detecting a secret intervention. Our estimates lead to a clear identification of the factors favoring the detection of interventions by FX traders. Not surprisingly, large, concerted and frequent interventions are much more easily detected than small, unilateral and sporadic ones (amount, coord and cluster have positive significant coefficients). The relevance of these three determinants is strongly supported by central bankers (see Neely, 2006). Successful interventions are also found to be more often spotted by FX traders than unsuccessful ones, which supports Dominguez (2004)'s conjecture (success also has a positive significant coefficient). Note that the estimates of the parameters in this nest are very robust to alternative specifications.

\section{Implications}

By modeling the whole process relative to FX intervention activity, our analysis has delivered insights that cannot be provided by separate investigations. The value added in terms of the implications of our work can be illustrated by two different examples.

First, our results suggest that the central bank (the BoJ) faces difficult problems when its previous interventions have failed to deliver the desired objective. To see this, suppose that, during the previous

\footnotetext{
${ }^{24}$ Recent changes in communication regimes at the BoJ are fully consistent with these findings. Under Sakakibara's management (1995-2000), very few secret operations were used (see Beine and Lecourt, 2004). After this period, the BoJ used much less oral communication and the proportion of secret operations increased strongly.
} 
weeks, the interventions conducted by the bank have not succeeded in moving the exchange rate in the desired direction. In this sense, the bank has a low degree of credibility. Assume also that the exchange rate is misaligned so that interventions are required. Our results indicate that (i) the bank will tend to intervene and (ii) it will favor the use of secret rather than public interventions. In this situation, only portfolio balance effects can be expected to work, which in turn suggests that large currency purchasing or selling amounts will be involved. However, large amounts increase the probability of interventions being detected, which would undermine the secrecy strategy. As a result, the central bank faces a tradeoff over the size of its interventions. This may also explain why it might be difficult to produce efficient interventions after a row of unsuccessful operations.

As a second example of the implications of this work, consider how communication policy interacts with exchange rate policy. When a central bank tends to communicate quite often, according to our results, it will favor public interventions. In this case, since there is no real detection process being undertaken by traders, the central bank can buy or sell large amounts of foreign currency. This is exactly what was observed for the BoJ during the Sakakibara period (1996-2002), when oral communication was often used alongside large and public interventions against the USD (Ito, 2003). ${ }^{25}$

These two examples suggest that the various determinants of the intervention process interact strongly. They show that the central bank's decision making involves a set of decisions rather than a simple choice (to intervene or not to intervene). A full understanding of a given exchange rate policy requires a large set of considerations, directly and indirectly related to interventions, to be taken into account.

\section{Conclusion}

This paper has investigated the various steps undertaken by the BoJ when intervening on the YEN/USD market. We have studied the determinants of three outcomes: (i) the decision to intervene; (ii) the use of secret versus public interventions; and (iii) the detection of secret interventions by FX traders. The estimation procedure is based on a nested logit specification with three different levels. The specificity of this framework allows us to consider the various outcomes in an integrated framework with a clear distinction between the levels.

Our results allow us to put previous empirical findings on the behavior of central banks in the FX markets into perspective. On the whole, FX authorities are found to intervene to reduce misalignments

\footnotetext{
${ }^{25}$ The so-called Sakakibara period includes the period during which Dr. Sakakibara was Director General of the International Bureau of the Ministry of Finance and therefore in charge of the FX intervention of the BoJ. This period also includes the period of office of his successor, i.e. Mr. Kuroda who basically followed the same type of intervention policy (see Ito and Yabu, 2004 on this). If we compare the Sakakibara period with the period between 1991 and 1995 on the one hand, and the period after 2002 on the other hand, we observe striking differences. About two thirds of the official statements were made during the Sakakibara period, which leads many observers to consider it as a period of high transparency and communication. Almost all interventions during that period are found to be public, while for the other periods, the proportions amount to $83 \%$ and $19 \%$ respectively. Finally, the average size of daily interventions amounts to 519 billions of JPY during this period, compared to 46.75 and 273.38 billions of JPY during the first and the last period respectively. The largest FX operation carried out by the BoJ also occurred during this period, more precisely on the 10 th of April 1998 when the BoJ sold more than 20 billions of US dollars.
} 
and to use their communication policy to further clarify their objectives. Once the decision to intervene has been taken, the characteristics of the intervention depends on market conditions and the central bank's overall credibility. That is, visible operations are used when trying to reverse the prevailing trend, while the failure of previous interventions encourages the central bank to opt for secrecy. Importantly, a secret intervention has to remain undetected to ensure its consistency with the secrecy strategy. The way interventions are conducted is then of overwhelming importance in influencing market participants' detection process. In this respect, our estimates suggest that a central bank trying to keep its interventions undetected should choose to intervene unilaterally, with low amounts and in a sporadic way.

Our results also show that a full understanding of any intervention policy has to integrate a large set of variables influencing the three levels discussed above. For instance, investing low amounts to reduce the probability of detection of an intervention means that the portfolio and microstructure effects are deliberately weakened. In other words, the central bank worsens its chances of moving the FX trend successfully (which is the primary objective of the intervention). This puts the focus on a potential trade-off for the FX authorities between the necessity of influencing the exchange rate adequately, and consistency with its general intervention strategy. Importantly, this dilemma only emerges when secrecy is required. This might partially explain the well-known reduction in the effectiveness of opaque policy.

This reasoning illustrates the necessity of adopting a global approach to analyzing central banks' behavior. More generally, it might open the door to further research. In particular, it would be interesting to investigate in more detail the influence of constraints such as the objectives of exchange rate and strategy on the critical amount invested in each intervention.

Finally, while our results are specifically related to the BoJ's intervention policy, we believe that they shed some interesting light on key variables influencing the exchange rate policy decisions of central banks in general. Most of the results we obtained are consistent with the opinions of a large number of central bankers about the appropriate way to intervene in the FX markets. 


\section{References}

Almekinders, G. J., 1995, Foreign Exchange Intervention: Theory and Evidence, Cheltenham: Edward Elgar Publishing Ltd.

Almekinders, G. J. and S. C. W. Eijffinger, 1996, A friction model of daily Bundesbank and Federal Reserve intervention, Journal of Banking and Finance, 20, 1365-1380.

Andersen, T., T. Bollerslev, F. Diebold and P. Labys, 2001, The distribution of realized exchange rate volatility, Journal of the American Statistical Association, 96, 42-55.

Andersen, T., T. Bollerslev, F. Diebold and P. Labys, 2002, Modeling and forecasting realized volatility, Econometrica, 71, 579-625.

Baillie, R. and W. P. Osterberg, 1997, Why do central banks intervene?, Journal of International Money and Finance, 16(6), 909-919.

Beine, M., A. Bénassy-Quéré and C. Lecourt, 2002, Central bank intervention and foreign exchange rates: new evidence from FIGARCH estimations, Journal of International Money and Finance, 21, $115-144$.

Beine, M. and O. Bernal, 2006, Why do central banks intervene secretly ? Preliminary evidence from the BoJ, Journal of International Financial Markets, Institutions and Money, forthcoming.

Beine, M., G. Janssen and C. Lecourt, 2004, Should central bankers talk to the FX markets?, SSRN Working Paper No. 505922.

Beine, M. and C. Lecourt, 2004, Reported and secret interventions in the foreign exchange markets, Finance Research Letters, 1(4), 215-225.

Ben-Akiva, M., 1973, Structure of passenger travel demand models, PhD thesis, Department of Civil Engineering, MIT.

Ben-Akiva, M. and M. Bierlaire, 1999, Discrete choice methods and their applications to short term travel decisions, Handbook of Transportation Science, 23.

Bénassy-Quéré, A., P. Duran-Vigneron, A. Lahrèche-Revil and V. Mignon, 2004, Burden sharing and exchange rate misalignments within the Group of Twenty, CEPII Working Paper No 2004-13, 2004-13.

Bernal, O., 2006, Do interactions between political authorities and central banks influence FX interventions? Evidence from Japan, DULBEA Working Paper No. 06-03.RS.

Bernal, O. and J.-Y. Gnabo, 2006, Talks, financial operations or both? Generalising central banks' FX reaction functions, SSRN Working Paper No. 932566. 
Bhattacharya, U. and P. Weller, 1997, The advantage to hiding one's hand: speculation and central bank intervention in the foreign exchange market, Journal of Monetary Economics, 39, 251-277.

Bonser-Neal, C. and G. Tanner, 1996, Central bank intervention and the volatility of foreign exchange rates: evidence from the options market, Journal of International Money and Finance, 15(6), 853-878.

Chiu, P., 2003, Transparency versus constructive ambiguity in foreign exchange intervention, BIS Working Paper No. 144.

Daly, A., 1987, Estimating "tree" logit models, Transportation Research B, 21(4), 251-268.

Dominguez, K., 1998, Central bank intervention and the exchange rate volatility, Journal of International Money and Finance, 18, 161-190.

Dominguez, K., 2003, The market microstructure of central bank intervention, Journal of International Economics, 59, 25-45.

Dominguez, K., 2004, When do central bank intervention influence intradaily and longer-term exchange rate movements?, Journal of International Money and Finance, forthcoming.

Dominguez, K. and J. A. Frankel, 1993, Does foreign exchange intervention work?, Institute for International Economics, Washington DC.

Evans, M. D. D. and R. K. Lyons, 2001, Portfolio balance, price impact, and secret interventions, NBER Working Paper No. 8356.

Fatum, R. and M. Hutchinson, 2002, ECB foreign exchange intervention and the euro: institutional framework, news and intervention, Open Economies Review, 13, 413-425.

Fratzscher, M., 2004, Communication and exchange rate policy, ECB Working Paper No. 363.

Galati, G., P. Higgins, O. Humpage and W. Melick, 2006, Option prices, exchange market intervention and the expectations channel: A user's guide, Paper presented at conference on exchange rate intervention: theory and practice, Cambridge, September.

Galati, G. and W. Melick, 1999, Perceived central bank intervention and market expectations: an empirical study of the yen/dollar exchange rate, BIS Working Paper No. rr.

Gnabo, J.-Y., S. Laurent and C. Lecourt, 2006, Does transparency in central bank intervention policy bring noise in the FX market?, SSRN Working Paper No. 932986.

Gnabo, J.-Y. and C. Lecourt, 2005, How transparent is the intervention exchange rate policy of the Bank of Japan?, SSRN Working Paper No. 839188. 
Hausman, J. and D. McFadden, 1984, Specification tests for the multinomial logit model, Econometrica, 52(5), 1219-1240.

Hung, J., 1997, Intervention strategies and exchange rate volatility: a noise trading perspective, Journal of International Money and Finance, 16, 779-793.

Ito, T., 2003, Is foreign exchange intervention effective? The Japanese experience in the 1990's, Monetary History, Exchange Rates and Financial Markets, Essays in Honour of Charles Goodhart, Paul Mizen (ed.), 2, 126-153.

Ito, T., 2006, Myths and reality of foreign exchange interventions: an application to Japan, Paper presented at conference on exchange rate intervention: theory and practice, Cambridge, September.

Ito, T. and T. Yabu, 2004, What promotes Japan to intervene in the forex market? A new approach to a reaction function, Journal of International Money and Finance, forthcoming.

Jansen, D. and J. de Haan, 2005, Talking heads: the effects of ECB statements on the euro-dollar exchange rate, Journal of International Money and Finance, 24, 343-361.

Kearns, J. and R. Rigobon, 2005, Identifying the efficacy of central bank interventions: evidence from Australia and Japan, Journal of International Economics, 66(1), 31-48.

Lyons, R., 2001, The Microstructure Approach to Exchange Rates, The MIT Press.

Maddala, G., 1983, Limited Dependent and Qualitative Variables in Econometrics, Econometric Society Monographs, 3, Cambridge.

McFadden, D., 1984, Econometric analysis of qualitative response models, Handbook of Econometrics, 11.

Neely, C. J., 2001, The practice of central bank intervention: looking under the hood, Federal Reserve Bank of Saint Louis Review, 83(3), 1-10.

Neely, C. J., 2006, Authorities' Beliefs about Foreign Exchange Intervention: Getting Back to the Hood, Federal Reserve Bank of Saint Louis Working Paper No. 2006-045A.

Oberlechner, T. and S. Hocking, 2004, Information sources, news and rumors in financial markets: insights into the foreign exchange market, Journal of Economic Psychology, 25, 407-424.

Pagan, A., 1984, Econometric issues in the analysis of regressions with generated regressors, International Economic Review, 25, 221-247.

Sarno, L. and M. Taylor, 2001, Official intervention in the foreign exchange market: is it effective and, if so, how does it work?, Journal of Economic Literature, 39(3), 839-868. 
Small, K. and C. Hsiao, 1985, Multinomial logit specification tests, International Economic Review, 26, $619-627$.

Vitale, P., 1999, Sterilized central bank intervention in the foreign exchange market, Journal of International Economics, 49 (3), 245-269.

Vitale, P., 2006, A Crtical Appraisal of Recent Developments in the Analysis of Foreign Exchange Intervention, CEPR Working Paper, 5729. 


\section{CESifo Working Paper Series}

(for full list see www.cesifo-group.de)

1836 Peter Backé and Cezary Wójcik, Catching-up and Credit Booms in Central and Eastern European EU Member States and Acceding Countries: An Interpretation within the New Neoclassical Synthesis Framework, October 2006

1837 Lars P. Feld, Justina A.V. Fischer and Gebhard Kirchgaessner, The Effect of Direct Democracy on Income Redistribution: Evidence for Switzerland, October 2006

1838 Michael Rauscher, Voluntary Emission Reductions, Social Rewards, and Environmental Policy, November 2006

1839 Vincent Vicard, Trade, Conflicts, and Political Integration: the Regional Interplays, November 2006

1840 Erkki Koskela and Mikko Puhakka, Stability and Dynamics in an Overlapping Generations Economy under Flexible Wage Negotiation and Capital Accumulation, November 2006

1841 Thiess Buettner, Michael Overesch, Ulrich Schreiber and Georg Wamser, Taxation and Capital Structure Choice - Evidence from a Panel of German Multinationals, November 2006

1842 Guglielmo Maria Caporale and Alexandros Kontonikas, The Euro and Inflation Uncertainty in the European Monetary Union, November 2006

1843 Jan K. Brueckner and Ann G. Largey, Social Interaction and Urban Sprawl, November 2006

1844 Eytan Sheshinski, Differentiated Annuities in a Pooling Equilibrium, November 2006

1845 Marc Suhrcke and Dieter Urban, Are Cardiovascular Diseases Bad for Economic Growth?, November 2006

1846 Sam Bucovetsky and Andreas Haufler, Preferential Tax Regimes with Asymmetric Countries, November 2006

1847 Luca Anderlini, Leonardo Felli and Andrew Postlewaite, Should Courts always Enforce what Contracting Parties Write?, November 2006

1848 Katharina Sailer, Searching the eBay Marketplace, November 2006

1849 Paul De Grauwe and Pablo Rovira Kaltwasser, A Behavioral Finance Model of the Exchange Rate with Many Forecasting Rules, November 2006

1850 Doina Maria Radulescu and Michael Stimmelmayr, ACE vs. CBIT: Which is Better for Investment and Welfare?, November 2006 
1851 Guglielmo Maria Caporale and Mario Cerrato, Black Market and Official Exchange Rates: Long-Run Equilibrium and Short-Run Dynamics, November 2006

1852 Luca Anderlini, Leonardo Felli and Andrew Postlewaite, Active Courts and Menu Contracts, November 2006

1853 Andreas Haufler, Alexander Klemm and Guttorm Schjelderup, Economic Integration and Redistributive Taxation: A Simple Model with Ambiguous Results, November 2006

1854 S. Brock Blomberg, Thomas DeLeire and Gregory D. Hess, The (After) Life-Cycle Theory of Religious Contributions, November 2006

1855 Albert Solé-Ollé and Pilar Sorribas-Navarro, The Effects of Partisan Alignment on the Allocation of Intergovernmental Transfers. Differences-in-Differences Estimates for Spain, November 2006

1856 Biswa N. Bhattacharyay, Understanding the Latest Wave and Future Shape of Regional Trade and Cooperation Agreements in Asia, November 2006

1857 Matz Dahlberg, Eva Mörk, Jørn Rattsø and Hanna Ågren, Using a Discontinuous Grant to Identify the Effect of Grants on Local Taxes and Spending, November 2006

1858 Ernesto Crivelli and Klaas Staal, Size and Soft Budget Constraints, November 2006

1859 Jens Brøchner, Jesper Jensen, Patrik Svensson and Peter Birch Sørensen, The Dilemmas of Tax Coordination in the Enlarged European Union, November 2006

1860 Marcel Gérard, Reforming the Taxation of Multijurisdictional Enterprises in Europe, "Coopetition" in a Bottom-up Federation, November 2006

1861 Frank Blasch and Alfons J. Weichenrieder, When Taxation Changes the Course of the Year - Fiscal Year Adjustments and the German Tax Reform 2000/2001, November 2006

1862 Hans Jarle Kind, Tore Nilssen and Lars Sørgard, Competition for Viewers and Advertisers in a TV Oligopoly, November 2006

1863 Bart Cockx, Stéphane Robin and Christian Goebel, Income Support Policies for PartTime Workers: A Stepping-Stone to Regular Jobs? An Application to Young LongTerm Unemployed Women in Belgium, December 2006

1864 Sascha O. Becker and Marc-Andreas Muendler, The Effect of FDI on Job Separation, December 2006

1865 Christos Kotsogiannis and Robert Schwager, Fiscal Equalization and Yardstick Competition, December 2006

1866 Mikael Carlsson, Stefan Eriksson and Nils Gottfries, Testing Theories of Job Creation: Does Supply Create Its Own Demand?, December 2006 
1867 Jacques H. Drèze, Charles Figuières and Jean Hindriks, Voluntary Matching Grants Can Forestall Social Dumping, December 2006

1868 Thomas Eichner and Marco Runkel, Corporate Income Taxation of Multinationals and Unemployment, December 2006

1869 Balázs Égert, Central Bank Interventions, Communication and Interest Rate Policy in Emerging European Economies, December 2006

1870 John Geweke, Joel Horowitz and M. Hashem Pesaran, Econometrics: A Bird's Eye View, December 2006

1871 Hans Jarle Kind, Marko Koethenbuerger and Guttorm Schjelderup, Taxation in TwoSided Markets, December 2006

1872 Hans Gersbach and Bernhard Pachl, Cake Division by Majority Decision, December 2006

1873 Gunther Schnabl, The Evolution of the East Asian Currency Baskets - Still Undisclosed and Changing, December 2006

1874 Horst Raff and Michael J. Ryan, Firm-Specific Characteristics and the Timing of Foreign Direct Investment Projects, December 2006

1875 Jukka Pirttilä and Håkan Selin, How Successful is the Dual Income Tax? Evidence from the Finnish Tax Reform of 1993, December 2006

1876 Agnieszka Stążka, Sources of Real Exchange Rate Fluctuations in Central and Eastern Europe - Temporary or Permanent?, December 2006

1877 Xavier Calsamiglia, Teresa Garcia-Milà and Therese J. McGuire, Why do Differences in the Degree of Fiscal Decentralization Endure?, December 2006

1878 Natacha Gilson, How to be Well Shod to Absorb Shocks? Shock Synchronization and Joining the Euro Zone, December 2006

1879 Scott Alan Carson, Modern Health Standards for Peoples of the Past: Biological Conditions by Race in the American South, 1873 - 1919, December 2006

1880 Peter Huber, Michael Pfaffermayr and Yvonne Wolfmayr, Are there Border Effects in the EU Wage Function?, December 2006

1881 Harry Flam and Håkan Nordström, Euro Effects on the Intensive and Extensive Margins of Trade, December 2006

1882 Panu Poutvaara and Mikael Priks, Hooliganism in the Shadow of the 9/11 Terrorist Attack and the Tsunami: Do Police Reduce Group Violence?, December 2006

1883 Ruud A. de Mooij and Gaëtan Nicodème, Corporate Tax Policy, Entrepreneurship and Incorporation in the EU, December 2006 
1884 Johannes Becker and Clemens Fuest, Corporate Tax Policy and International Mergers and Acquisitions - Is the Tax Exemption System Superior?, January 2007

1885 Momi Dahan and Udi Nisan, The Effect of Benefits Level on Take-up Rates: Evidence from a Natural Experiment, January 2007

1886 José García-Solanes, Francisco I. Sancho-Portero and Fernando Torrejón-Flores, Beyond the Salassa-Samuelson Effect in some New Member States of the European Union, January 2007

1887 Peter Egger, Wolfgang Eggert and Hannes Winner, Saving Taxes Through Foreign Plant Ownership, January 2007

1888 Timothy J. Goodspeed and Andrew Haughwout, On the Optimal Design of Disaster Insurance in a Federation, January 2007

1889 Wim Groot, Henriëtte Maassen van den Brink and Bernard van Praag, The Compensating Income Variation of Social Capital, January 2007

1890 Bas Jacobs, Ruud A. de Mooij and Kees Folmer, Analyzing a Flat Income Tax in the Netherlands, January 2007

1891 Hans Jarle Kind, Guttorm Schjelderup and Frank Stähler, Newspapers and Advertising: The Effects of Ad-Valorem Taxation under Duopoly, January 2007

1892 Erkki Koskela and Rune Stenbacka, Equilibrium Unemployment with Outsourcing under Labour Market Imperfections, January 2007

1893 Maarten Bosker, Steven Brakman, Harry Garretsen, Herman de Jong and Marc Schramm, The Development of Cities in Italy 1300 - 1861, January 2007

1894 Michel Beine, Oscar Bernal, Jean-Yves Gnabo and Christelle Lecourt, Intervention Policy of the BoJ: A Unified Approach, January 2007 